\title{
The need for a standard qualification of ICT professional competences
}

\author{
The reasons that urged CEPIS to create the EUCIP model \\ are even more pressing today than they were in 2000
}

\author{
Paolo Schgör \\ Certifications manager at AICA, Italy, p.schgor@aicanet.it
}

\begin{abstract}
Standards are, generally speaking, a sensible way of simplifying a number of issues; this is also true for ICT professional competences, the standardization of which could bring huge benefits to all stakeholders, including education \& training providers, employers, candidates and agencies for employment, freelance professionals, ICT associations, governmental and statistical institutions, and - finally - the ICT industry at large. The EUCIP model is certainly one of the most interesting proposals for a possible multi-stakeholder solution to this incredibly complex issue.
\end{abstract}

Keywords: Europe, ICT certifications, ICT competences, professionalism, professional societies, standardization

\section{The Need for Standards in ICT}

\subsection{Standards in a Layman's View}

I'm not sure whether a specific professionalism regarding the definition of standards has ever been defined (or even can be); anyway, I do not consider myself a professional "standardizer", and the following introductory statements are offered as a layman's view.

On the other hand, I have been progressively involved in international teams and task forces having an implicit - or sometimes explicit - focus on the definition of standards around ICT competences; thus, the main part of this script is dedicated to the description of the current proposals devised by CEPIS on this subject. 
My thesis is that having one recognized standard may not be a vital issue, but it is much better than having several.

I don't even want to take into account the total absence of standards, simply because this means somehow that anyone decides one's own (possibly a different one every time): all these cases can be seen as degenerate forms of "several" standards.

Just a couple of trivial examples taken from personal "ICT user" experience: a negative instance and a positive one.

- Negative: every traveller knows the frustration related to the absence of one global standard for electric power plugs; if you carry a laptop computer or any other mobile device, it is usually much easier to get connected to the Internet (by wired or wireless access protocols) than getting your device's battery recharged!

The only currently available solution is to use specific adapters (see picture) that reflect the need for a "translation" between conflicting local standards about the physical shape of sockets and plugs.

- Positive: the recent victory of the Blu-ray Disc standard over the HD DVD standard is generally seen as a quite beneficial outcome of the Sony-versus-Toshiba conflict on formats for High Definition movies in the "Home Theater" consumer market.

Regardless of who wins and who looses, and leaving asides disputes on which format was better (in terms of technical features, quality, prices, flexibility, de facto market position, etc.), most analysts agree on the positive effects of Toshiba's unexpected surrender, that crowns Blu-ray as the industry standard; all players - including Toshiba, Nec and the other partners in the loosing front - are now expected to benefit, more or less, sooner or later, from a faster-growing market.

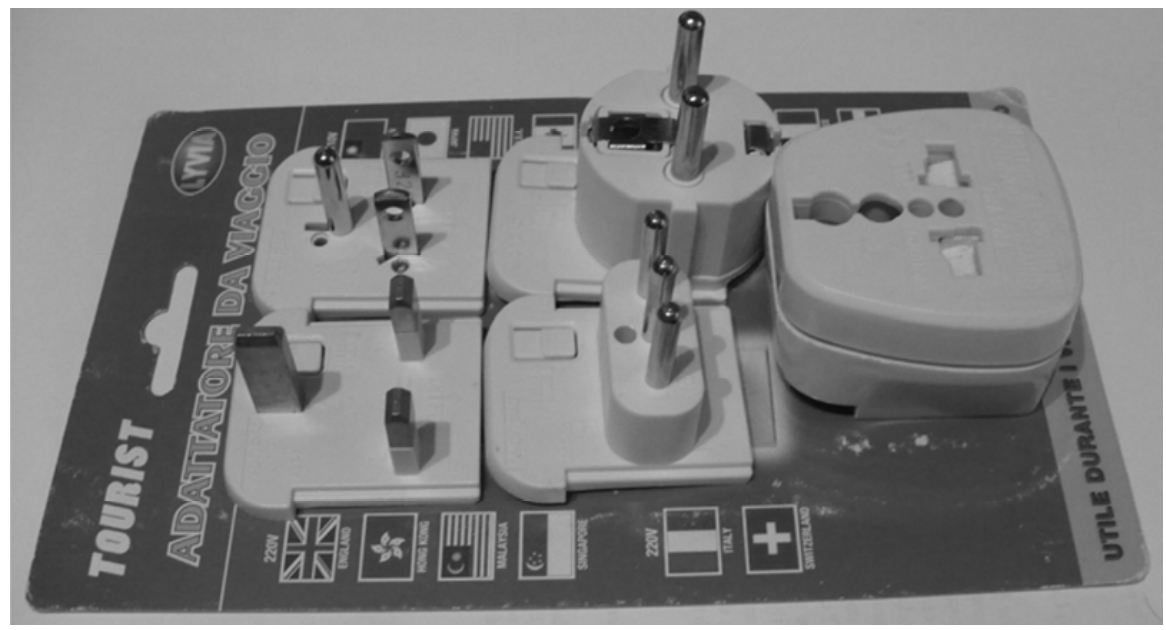


From a user's perspective, in the short term it might be really annoying to be forced to change a previously adopted standard, if the match winner is not "yours"; but in the medium and long term, the benefits of cross-border, crossproducer, cross-anything compatibility exceed by far the nuisance caused by a possible transition.

\subsection{The Idea of a Standard Structure for the ICT Profession}

The idea of establishing a European common ground for the definition of ICT professionalism and for the classification of related professional skills is now 20 years old: as a matter of fact, some records [1] of such discussions between Computer Societies date back to 1988. In that year, during an IFIP Congress in Rio de Janeiro, the delegates from 8 European countries started thinking of a possible cooperation, having in mind the increasing role of the future European Union in national policies. Still in 1988, a 'historical' meeting in London set the basis both for the foundation of CEPIS (whose Articles of Association were signed in 1991) and for the development of a European Informatics Skills Structure, EISS, then published in May 1992 [2] with the following subtitle: "A Set of Performance Standards Covering all Functional Areas of Work Carried out by Professionals in Informatics".

In other words, the idea of a standard framework for the ICT profession was born in the very same moment as CEPIS, and by the same parents, so that they can be thought of as twins: and there's no surprise in considering that the need for an international standard rose in a climate that was strongly conditioned by expectations on the announced progressive convergence of 12 independent states into a new European Union (officially signed-off with this name at Maastricht, on 7 February 1992). With some simplification, we might say that such cross-border standardization attempts are a consequence of a perceived enlarged market space for ICT professionals.

If this was true in 1988, it is even more pressing today, 20 years later, when a progressive globalization seems to be inevitable, whatever you may think of it.

\subsection{Further European Endeavours}

In more recent times, starting with the new millennium, several different initiatives addressed the issue of a unified approach to ICT professional skills. I'll mention here only the four most significant attempts that had (or still do have) an explicit ambition to formulate super-national proposals at a European level.

Career Space: this initiative rose during the hype of the so-called new economy, when ICT companies had very serious problems in finding new graduates to hire; half a dozen of the major multinationals created the Career Space consortium and 
specified 18 Generic Skills Profiles; their goals were both to describe the characteristics of some typical ICT jobs in an interesting way (so as to attract young people), and to drive the attention of universities to the most critical subjects that the ICT employers could hardly find in a graduate's preparation. A very practical approach led to a set of deliverables which are interesting in terms of ICT skills requirements (directly described from the demand side of the job market), yet poor in terms of scientific rigour; however, the results produced by this consortium were adopted by CEN (see below) and incorporated in CWA 14925 and CWA 15005.

e-Skills Forum: in parallel with the rise of the Career Space initiative, the European Commission launched the e-Skills Forum, and asked the Governments of EU member states to appoint an official national delegate for discussions in the area of ICT skills and their improvement through e-learning. The main merit of this very interesting initiative is to facilitate the dialogue between stakeholders.

e-SCC / ILB: following the launch of the e-Skills Forum, the main international operators offering ICT certification formed a consortium called e-Skills Certification Consortium (e-SCC), which was recently replaced by the Industry Leadership Board (ILB); its the main goal is to support the concept of "MultiStakeholder Partnership" initiatives, involving public and private entities in joint projects bringing tangible results in the diffusion of key ICT competences.

CEN/ISSS: CEN is the European Centre for Standardization, and the specific ISSS line of business focuses on an Information Society Standardization Structure. CEN members are the national standards bodies of Austria, Belgium, Cyprus, Czech Republic, Denmark, Estonia, Finland, France, Germany, Greece, Hungary, Iceland, Ireland, Italy, Latvia, Lithuania, Luxembourg, Malta, Netherlands, Norway, Poland, Portugal, Romania, Slovakia, Slovenia, Spain, Sweden, Switzerland and United Kingdom.

Within CEN/ISSS a stable "workshop" is dedicated to ICT skills, and it is managed with the support of the European Commission (DG Enterprise), Cedefop (the Centre for the Development of Vocational Training, a EU agency) and CEPIS.

Since 2004, the CEN/ISSS Workshop involved several stakeholders, and reached consensus about some intermediate results: the afore mentioned recognition of Career Space results, plus a document on an "ICT Skills MetaFramework" (CWA 15505) recognizing the relevance of various national frameworks, namely SFIA in the UK, AITTS in Germany, and CIGREF Nomenclature in France.

Although this is currently the most serious endeavour to define a European standard, unfortunately the Workshop does not seem to be in a position to achieve results that can really be used to address the practical issues of ICT skills management. This is, of course, a personal opinion, but it could be supported by 
two arguments: firstly, the discussion is more and more abstract and far from the ICT domain (the main focus seems to be on terminology and methodological issues); secondly, there is an insufficient commitment of some of the main stakeholders, i.e. the various authorities working on national/local qualification standards and the international operators offering ICT certification.

In any case, the problem is really complex, also due to the reasons presented in the next section.

\subsection{Factors Affecting the Complexity of Resolution}

The definition of a standard system for the qualification of ICT professional competences is not a trivial subject: it requires a large team of experts who can guarantee a reasonable coverage of all technical aspects of the ICT domain, plus a few experts in the definition of a coherent and balanced framework. Yet, the most arduous factors of complexity in having a standard accepted seem to be the political aspects: a list of such factors is presented here.

Multiple purposes: as pointed out by Matthew Dixon [3], classification of professional profiles and competences are relevant for a number of different applications, and e-competence frameworks typically reflect a specific purpose for which they were designed.

Ministerial jurisdiction: for the same reason mentioned just above, different governmental departments (Education, Industry, Trade and Competition, Labour, Justice...) are involved in the definition of competence standards.

Territorial jurisdiction: several levels of local autonomy exist, and there's no common consent on whose guidelines are binding. In the worst cases, we could think of 5 or 6 levels of local authorities defining norms:

- global (ISO norms, UNO resolutions...),

- “continental union” level (by EU, NAFTA...),

- national (in France, Germany, Italy, UK...),

- "regional" (in Bavaria, Lombardy, Scotland...),

- "sub-regional” (French departments, Italian provinces, UK counties),

- township...

In the recent past, the hierarchy was certainly led by the national governance, with possible recommendations from international bodies and some tolerance for minor local adjustments. Nowadays, in Europe, two diverging trends seem to be shifting more authority both to super-national entities (the EU) and to regional governments. 
Sectoral and corporate-level jurisdiction: many standards - including the above mentioned Blu-ray Disc format - come from industry associations or even from single companies; eventually, if they find a clear way ahead, they are officially recognized as official norms and sometimes referenced by specific laws.

Notwithstanding all of the above complexity factors, a solution could (and should) be found. It is a fact that a number of large companies and Public Administration entities are working separately on these issues, and it would be nonsense not to join forces and continue to restart every time from scratch. Unfortunately, this is still the current practice.

\section{The EUCIP Model}

\subsection{Origins and Parallel Developments}

The EUCIP model, briefly presented here, can be seen as the result of two decades of work done by CEPIS, the Council of European Professional Informatics Societies, through task forces involving several Member Societies from various countries.

In such a considerable time period (compared to the very recent history of ICT) some words have changed, so that what was once referred to as "skills structure" would now be called "competence framework", but the concept is basically still the same: to provide a comprehensive reference for classifying and qualifying the various elements of knowledge, ability and demonstrated professional performance characterizing an ICT professional.

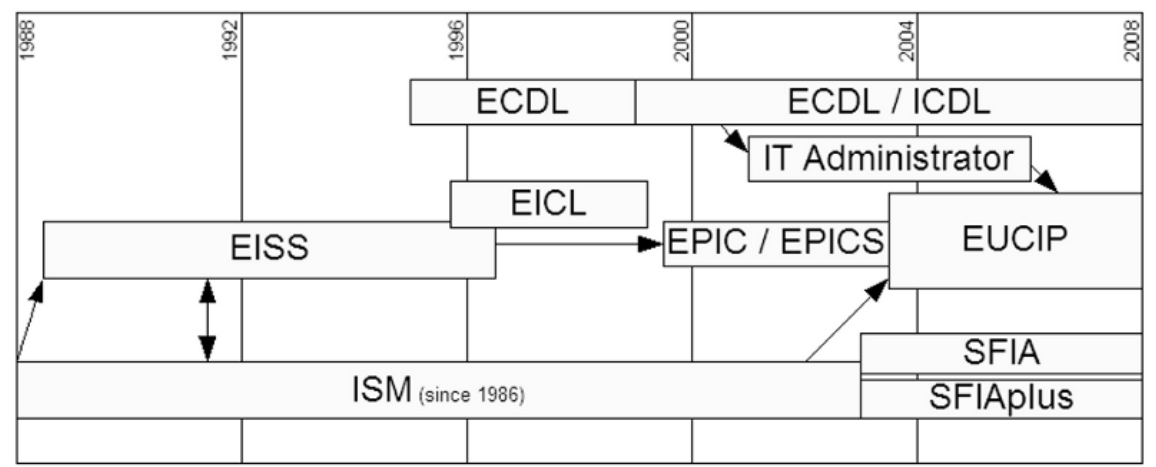

The figure shows how CEPIS's efforts are inspired and supported by parallel activities promoted by the British Computer Society (BCS), whose leading position within CEPIS was always recognized. Nevertheless, a distinction between 
UK-centric and Europe-wide proposals and applications was constantly kept, also taking into account the different institutional stakeholders (i.e. the Crown in UK, the European Commission in the EU, etc.).

Although each project would deserve a dedicated explanation, we will just take a single instance that gives an idea of the interlacement between different initiatives, which is much more complex than the figure can render.

The IT Administrator certification programme was first conceived as a unification of two separate ideas: based on several inputs from the market, the ECDL Foundation had involved experts from Greece, Ireland and the UK in the initial definition of an "ECDL Advanced Specialised" programme (something in the middle between ICT user skills and professional skills certification); in the meanwhile, the Italian government had asked AICA to develop the guidelines of a LAN administrator profile for decentralized branches of Public Administration entities. The task forces merged, and a single product - with 5 certification modules - was developed. A few years later, the experts working at the definition of the European Certification of Informatics Professionals (EUCIP) approved the merger of the IT Administrator programme into the EUCIP programme itself.

The whole new model was built with direct inputs from all of the above shown CEPIS-internal efforts and the experts involve were fully aware of the various endeavours listed under the subtitle 2.3: EUCIP can therefore be considered as an original synthesis of a number of different researches and initiatives.

\subsection{Specific Features of the EUCIP Model}

The EUCIP model synthesizes many previous and parallel works. The originality of such a synthesis is primarily related to the specific viewpoint of the expert groups that defined it: they were formed by ICT professionals, university professors and managers of international certification programmes, who had in mind both the theory of informatics and the business view of ICT; the main focus was on certification (drawing from the ECDL/ICDL experience and from constant research on the ICT certification market).

As a consequence, EUCIP is extremely ICT specific (hardly portable to different industries), vendor independent, but it acknowledges a high role to technology providers, business oriented, having a focus on applied technology for business effective information systems, and practical-minded, because all professional skills requirements were specified with a concern on possible examination forms.

From an academic point of view, the EUCIP model might be deemed weak in terms of "purity" in definitions, lacking in cross-sectoral generality, and scarce in the description of attitudes, behavioural skills and levels of responsibility: in my view, these are not really disadvantages, but characteristics associated with a model focusing on ICT skills. 
EUCIP defines a Core Level (the inner circle in the figure below); this might be intended as the common body of knowledge that any ICT professional should be familiar with. The competence requirements specified in the Core Level syllabus are grouped into 3 knowledge areas, which correspond to the main phases in an Information System's life cycle: plan, build, and operate.

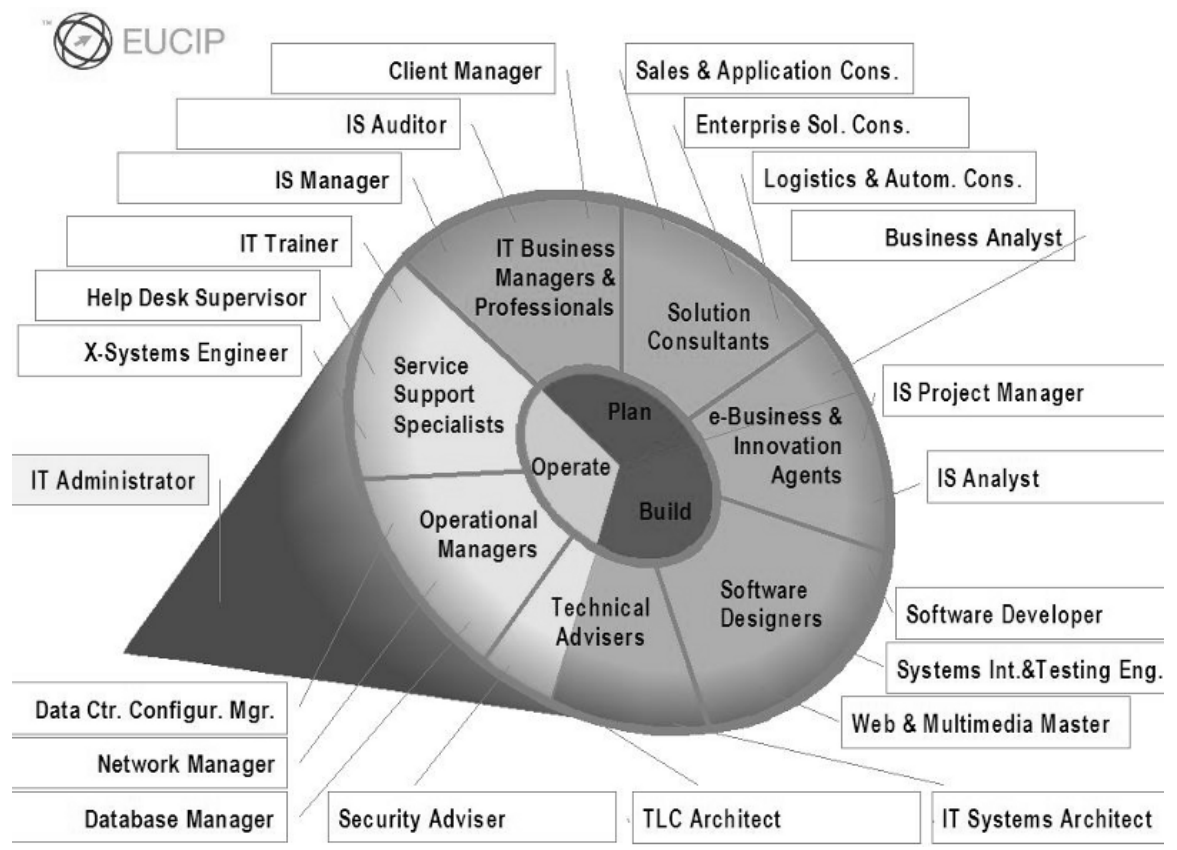

The total number of competence items specified for the core level is around 500, grouped into ca. 100 topics, further grouped into 18 categories, each of which belongs to one of the 3 main knowledge areas.

In addition to the Core Level, an ICT professional should be characterized by a specialisation, i.e. by deeper competence in some selected areas and categories (using the EUCIP terms). The EUCIP Professional Level certification can only be achieved by candidates who demonstrate additional competences earned through a mix of formal studies, "elective" certification modules (i.e. certificates issued by non-EUCIP organizations like Cisco, Microsoft etc.), plus some practical work experience. The EUCIP Professional Level defines 7 branches of professionalism and a total of 21 profiles; each of them is specified through a 20-page document, describing the typical tasks, the competence requirements and the cross reference to the classification systems used in the 4 main European countries.

The total number of competence items specified at the elective level is approximately 2500, grouped in over 150 categories, each of which refers to one of the 18 core categories. 
The IT Administrator programme includes 5 certification modules, that can either be seen as a stand-alone series or taken as elective modules in a candidate's progression towards one of the 21 elective profiles.

Most of the official documents specifying the EUCIP standard are publicly available without restrictions through CEPIS and ECDL Foundation's websites.

\subsection{Sample Applications and Benefits}

In this section, a few EUCIP application examples are listed; each of them could be described in a dedicated article, but our objective here is only to catch the variety of possible (and real!) uses of a standard model for ICT competences, on the supply side of ICT education and training, as well as on the demand side, i.e. for governmental organizations and private companies aiming at a more effective management of their human capital.

Cisco / EUCIP cooperation: in 2005 Cisco was looking for a third-party certification to be offered to the European students attending IT Essentials courses at a Cisco Networking Academy; after some talks with the ECDL Foundation, some further studies and pilot projects, three EUCIP IT Administrator modules were chosen as the best solution. As a consequence, the most recent version of Cisco's IT Essentials curriculum - produced in the USA - was enriched taking EUCIP syllabi as one of the main sources of input.

IT vocational training in Estonia: vocational high schools in Estonia (one of the most advanced EU states in e-Government innovation) have adopted the EUCIP Core syllabus as the main reference for ICT students.

EUCIP at the University: several universities (remarkably in Italy and Ireland) have compared the contents of their courses for ICT students with EUCIP syllabi; the typical outcome is that some more attention should be paid to the subjects grouped in the "Plan" area of EUCIP, i.e. to the value of IT from a business perspective. As a consequence, students are invited to complement their studies with some dedicated training, and to prove their competence by getting EUCIP certified.

Professional development in Norwegian companies: unlike all other countries, in Norway EUCIP has always been proposed firstly to non-ICT companies as a way to improve the professional value of their ICT staff. This means, in practice, that every EUCIP project was planned in co-operation with one or more companies, i.e. working on the demand side of ICT employment. 
EUCIP for ICT Governance in Italy: various Public Administration (PA) entities and governmental agencies in Italy have adopted EUCIP as the reference framework for ICT professional competences. Pilot projects have involved ICT employees of the Ministries of Finance, Defense, Justice, Education.

Italia Lavoro, the agency in charge of regulating the national employment market, has designed the national ICT professional profiles based on EUCIP profiles.

CNIPA, the governmental agency for ICT in PA, is about to release a complete set of guidelines for the procurement of ICT services, where professional profiles reflect EUCIP standards. It is likely that most invitations to tender from PA entities will recommend tenderers to refer to EUCIP profiles. By the way, some private organization like Generali, one of the largest Italian insurance groups, are working exactly in the same direction, recommending all internal ICT project managers and buyers to use EUCIP profiles as a benchmark when evaluating professional services proposals from their suppliers.

\section{Conclusion}

The EUCIP model offers a comprehensive set of concepts (including a body of knowledge for the whole scenario of ICT professions) and tools for an effective management of the human capital.

It can either be seen as a traditional certification offering (competing in a narrow market, where customers are disorientated by an excess of proposals) or as a shared model around which a number of stakeholders are finding solutions to the complex issues of professionalism and effective management of ICT competences and profiles.

The second option has an evident higher value, but the extent of its success depends only partly on CEPIS's ability to present the EUCIP "product": in fact, it mainly depends on an open attitude from other stakeholders, who can either exploit the value of this thorough model, or continue to conceive new projects from scratch, and cope with the arduous task of defining and measuring ICT professional competences.

\section{References}

1. Hamburg, Inge, 10 Years, CEPIS internal booklet, London, UK (1998).

2. CEPIS Task Force on Professional Qualifications and Development (led by the British Computer Society, 12 EU countries represented), European Informatics Skills Structure, CEPIS, Amsterdam, The Netherlands (1992).

3. Dixon, Matthew, "The potential Uses, Benefits and Costs of a European ICT Skills MetaFramework", Annex A to the CWA 15515: "European ICT Skills Meta-Framework - Stateof-the-Art review, clarification of the realities, and recommendations for next steps", CEN, Brussels, Belgium (2006). 